\title{
Structure soil stabilization with natural materials in the Russian Far East
}

\author{
Svetlana Zhdanova ${ }^{1}$, Aleksey Piotrovich ${ }^{1, *}$, and Andrey Moshenzhal $^{2}$ \\ ${ }^{1}$ Far Eastern State Transport University, 47 Seryshev St, Khabarovsk, 680021, Russia \\ ${ }^{2}$ LLC "Stroyimpuls", Bldg. 47, Wing 2, Stachek Ave., St. Petersburg, 198097, Russia
}

\begin{abstract}
The paper covers some results of scientific and practical use of different design-technological solutions developed by the Far East State Transport University on the basis of the local materials such as rock and clay soils or strengthening compositions from the rock refuse of local mineral resources. The latter are developed and introduced into practice by the authors for dewatering and stabilization of the swamp material in the roadbed and other earth structures. The lab research of the soils and examples of their uses are presented in diagrams. The paper covers the conclusions about feasibility and effectiveness of local material
\end{abstract}

\section{Introduction}

Severe natural-climatic, complex and unfavorable engineering-geological, permafrostsoil and hydro-geological conditions of the Far Eastern region are characterized by excess moisture and sharp changes in air and soil temperatures in depth [1,2]. Peculiar mountainand-valley landscapes, permafrost soils, geological structures, specific hydrogeological conditions, and high seismicity have caused and still cause a great amount of physical and geological phenomena that, in their turn, generate numerous subgrade deformations.

These factors are the main cause of deformation of weak soils and ground structures. This is especially true of weak and waterlogged silty and clay soils [3]. These circumstances require thorough permafrost monitoring, deep critical assessment of permafrost, and hydrogeological study at the icing spots, which are objective indicators for potential subgrade deformations.

As a rule water-logging of soils occurs during a prolonged contact with surface and ground waters. In this condition seasonal freezing-thawing of waterlogged soils leads to frost heaving and lowering deformation of structures, banking, washing of slopes, etc. The normalization of the temperature and humidity regime in the soil helps to eliminate deformities. The most effective measures of natural soil drainage are drainage systems. The first system effectively divert free water, the second one diverts connected water as well. But it is difficult to drain the connected water of soils in earth structures in this way because of their design features. Therefore the soils that are used in them are dried in other ways, for example, with the help of strengthening compositions based on mineral binders. Due to the

*Corresponding author: piotrovich@ rambler.ru 
introduction of mineral binders into the soil excessive moisture is spent on their hydration and cementation which contributes to the drying effect and, as a result, soil hardening [4-8].

The technical literature and world practice show that since the middle of the 20th century the most well-known and widely used methods of hardening and stabilizing soils that strengthen compositions in road construction are mainly based on Portland cement and similar materials.

The task of the authors was to obtain such strengthening compositions (SC) the introduction of which in the wet soil could lead to the equalization of temperature and humidity and later to the formation of a homogeneous soil monolith that will increase its strength. The materials that were supposed to be used were mineral active components made from the local raw resources of the Far East of Russia. Also, some useful engineering designs for ground structures stabilization in permafrost areas are discussed. These designs have advantages in comparison to designs of other authors because we are aware of local conditions of the region and take them into account in our research.

\section{Laboratory tests. Pilot application}

Strengthening compositions (SC) made from raw materials with the purpose of stabilizing the soil have been developed and implemented by the FESTU researchers since 2000. The original recipes of SC were developed and patented in the FESTU research laboratory "Subgrade and Foundations" (Patents RF NoNo 2125517, 2192517, 2236504, 2422577, etc.). The laboratory also studied reinforced soils. The goal was to obtain different compositions on the basis of local mineral raw materials for the stabilization of wetted clay soils of the roadbed. The objects of strengthening were slopes of road embankments and excavation; weak foundations of the roadbed, landslide slopes on which they are located. When selecting the components, the researchers sought to maximize the use of local mineral resources.

The compositions were selected experimentally and tested in the field and in the laboratory with various methods. In 2001, a business plan was drawn up for the production of strengthening compositions on an industrial scale and their delivery to the facilities of the Far Eastern railway. After that began the trial use of them on real objects (figure 1).

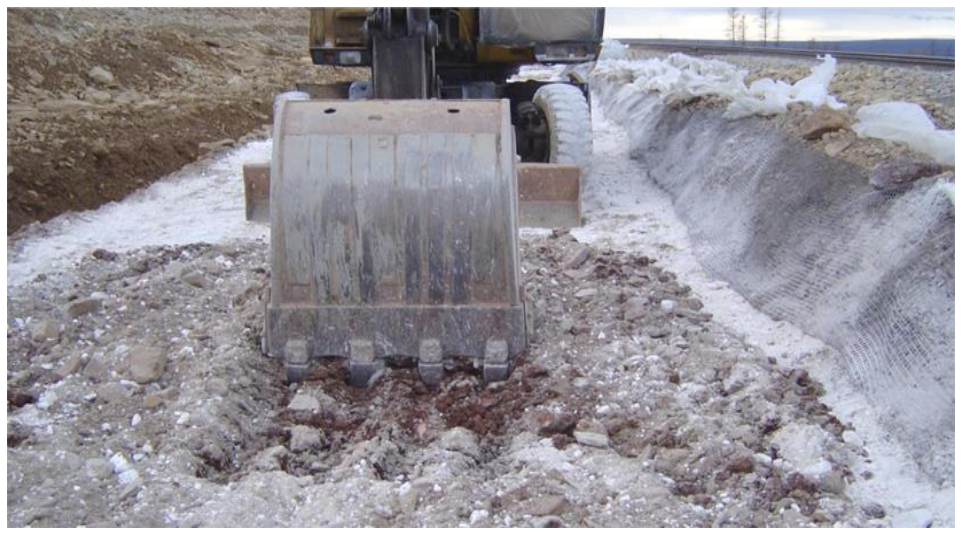

Fig. 1. The work on strengthening the soils on karst land of the railways in Yakutia.

There have been developed variations of SC the introduction of which into the waterlogged soil later leads to the formation of a homogeneous structure of the soil monolith. The strength of it increases due to the "crosslinking" of all its mineral components. As a result, the ground structure or its foundation is stabilized. Experimental studies of the results 
of the use of the SC on real objects have shown that the soil monolith increases over time, "grows" in depth, normalizing humidity and temperature in depth.

Strengthening compositions developed in FESTU dry and strengthen the soil due to specially selected components during the entire period of the facility operation. For solving this problem, variants of SC recipes were developed, which included the following components: astringent-dolomite lime and zeolite, enzyme-sealer-surfactants based on proteins and sugars. Additionally, there have been introduced the fillers: of a fine fraction limestone and screenings and of a larger fraction - crushed stone and screenings of solid rock. Depending on the properties of the reinforced soil, the percentage and components of SC varied. The results of experimental studies in the laboratory lead to dependencies (figure 2), confirming the effectiveness of soil stabilization by strengthening compositions.

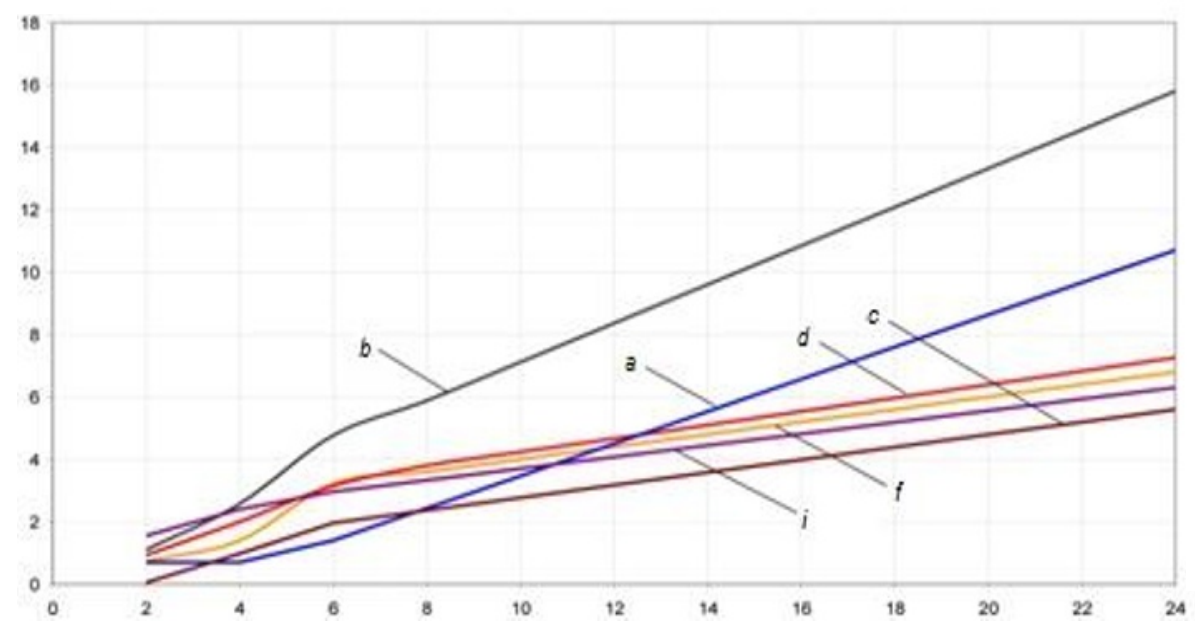

Fig. 2. Graphs of moisture loss at the temperature of the soil mixture production equal to $+25 \mathrm{C}$ and $+35 \mathrm{C}$ respectively: $\mathrm{a}$ and $\mathrm{b}$ - ordinary soil; $\mathrm{c}$ and $\mathrm{d}$-strengthened soil; $\mathrm{i}$ and $\mathrm{f}$ - soil under the strengthening layer.

Strengthening compositions are used on roads and railways of the Far East of the Russian Federation to perform the following engineering activities: strengthening and drainage of the foundations of road embankments, stabilization of collapsing slopes of excavation, strengthening the contact network supports, elimination of deep deformations of foundations of roadbeds and foundations of buildings and structures.

The results of this work were highly appreciated in the construction practice that used local mineral raw materials (for example, the silver medal award at the 6th Moscow International salon of innovations and investments for the development of "Design and manufacture of building materials (reinforcing and astringent compositions)", Moscow, 2006).

\section{Theoretical grounds}

Cementing soils using the known methods of water absorption leads to the dehydration of the strengthened layer. However, high strength characteristics, which are sufficient for conventional soils, are unattainable for waterlogged soils. Known strengthening compositions can be used only for soil moisture, characterized by plasticity of $W n$ of no more than $17 \%$. This happens due to the fact that with the transition to the greater direction of the optimal humidity range, the soil acquires a soft plastic state and ceases to condense. 
Laboratory tests have shown that the strength of samples with the new SC is 35-40 MPa. The introduction of a fine fraction of limestone and brucite into the soil leads to the formation of an equal structure of the soil monolith. This happens due to the formation of additional crystals of hydro aluminates $\mathrm{Ca}$ and $\mathrm{Mg}$. Clay and carbonate dust of limestone screenings, and the $\mathrm{Mg}$ cations and the hydroxyl group of brucite dust interacting with each other create a solid crystalline frame consisting of hydro aluminates $\mathrm{Ca}$ and $\mathrm{Mg}$, which "zips" the coarse fraction of the filler and the binder. This effect of the fine fraction of the filler leads to the formation and growth of an equally strong monolith over the entire volume of the strengthened soil.

A significant increase in strength occurs due to an increase in the adhesion of soil particles with a cementing agent. For example, a usual stacked contaminated gravel has low adhesion to the binder, as each of its stone is covered with a film of water and stone dust. In this case, the rubble has an inert surface with respect to the binder, which contributes to the destruction of the monolith on the contact "rubble-binder". Under the influence of the SC fine particles of screenings fill the macro pores, and the compaction of micro pores happens due to the enzyme-seal, which while removing water from the pore space contributes to the filling of this space of fine clay particles. Constant compaction and drying of the soil also contributes to the formation of a durable monolith. The dehumidification of wetted soils occurs due to the binding of unbound water with lime during soil cementation and adsorption of zeolite and brucite of excess water and bound water from the pore space

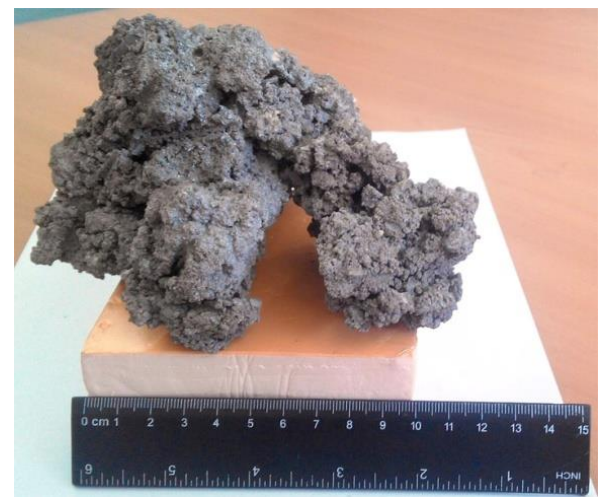

Fig. 3. The picture of the sample fixed soil.

The soil is constantly drained in a closed cycle: the hydration of dolomite lime - extraction of water by the enzyme and zeolite, which leads to the forced filling of the pore space between the soil particles with inclusions of organic and mineral particles - the transfer of water to the molecular state and, as a consequence, the drainage of the soil. Then the cycle repeats. As a result, the hardened soils form a soil conglomerate (figure 3) with high strength characteristics (the deformation module is 100-130 MPa) which retains strength for a long time under static and vibro-dynamic load.

An additional positive point is that the hardened soil conglomerate grows towards the moistened zones. In this case, a coral-like structure is formed, which improves adhesion to the rest of the array, for example, to a soil slope. A high degree of soil compaction is also achieved through the use of highly active surfactants in the composition.

As a result, the SC perform the following functions:

- reduction of soil moisture and plasticity;

- the conversion of colloidal clay particles into the crystal;

- providing dilution factor to $0,8-0,85$;

- ensuring frost resistance higher than Mfr 100;

- ensuring the density of $\mathrm{Cd}$ more than 1.1. 


\section{Practical implementation}

The experimental use of the SC has been carried out by the authors on the roads and railways of the Far East of the Russian Federation, civil and industrial construction sites since 2001. The example below complements the results of the practical use of the developed strengthening compositions and the technologies of their application to the soils of hardened structures given in a number of sources.

In October-November 2008, the FESTU research laboratory "Subgrades and Foundations" commissioned by the city administration of Khabarovsk held a geotechnical survey of the ground bases in the trenches in the areas of bulk soils prepared for the laying of external sewage at the construction site "The Group of houses on Slobodskaya - Sheronov streets in Khabarovsk".

The purpose of the work was the analysis and correction of design solutions for external water supply and sewerage (WSS) in the area of bulk soils. The scope of work included the following activities:

- soil sampling;

- laboratory tests of soil bases;

- development of proposals for the adjustment of design solutions and their coordination with the «Customer»;

- author's supervision, technical support;

- adjustment of design and estimate documentation

The options for strengthening the foundation soils were being considered while taking into account cost savings based on advanced resource-saving materials and structures tested at the experimental facilities and based on modern methods of stability calculations. The staff of the FESTU laboratory "Subgrades and Foundations" performed soil analysis for WSS, over $181.5 \mathrm{~m}$ in length on a plot of bulk soils.

30 monoliths and 20 samples of disturbed structure were selected to determine the full complex of physical characteristics of soils and the degree of compaction. 10 monoliths were selected for strengthening compositions for different soils.

Dynamic sensing was performed in 10 places so that to determine the actual degree of consolidation of the $K_{\mathrm{f}}$ for trenches prepared for laying of external sewerage networks and to establish the physical and mechanical characteristics of the soil at the base of the trenches to a depth of $4-5 \mathrm{~m}$.

4 monoliths were selected for the testing of strengthened soils. The results of the tests of the weak samples of strengthened soil showed that the deformation modulus E averaged 50 $\mathrm{MPa}$. The results of a visual inspection of the state of the opened trenches and the laboratory studies of the geotechnical properties of the samples selected in these trenches lead to the conclusion that the soil at the construction site is characterized as a dump of soils, industrial waste and household waste, i.e. as a bulk soil with a heterogeneous composition and compressibility.

Based on the analysis of the initial information, it was determined that the starting materials, which make up the bulk of the embankment, are loamy soils with a content of coarse fractions of crushed stone and gravel from 10 to $40 \%$. Stacking of soil in the dump was carried out to a depth of 10-12 m. The approximate age of the dumping at various sites ranges from 4 to 20 years. Given that the main source soil of the dump are loamy materials, they were attributed to non-decayed bulk clay soils according to the degree of compaction from its own weight. Their compaction process lasts from ten to thirty years.

The actual compaction coefficient of the bottom of the designed trench was 0.82 which indicates the need to strengthen or seal it before laying sewer pipes.

The original design solution of the company "KHABAROVSKGRAZHDANPROEKT" involved the construction of a concrete or pile foundation with the circumference of the pipe 
of 120o for laying pipes and sewers. In some cases it involved the construction of a reinforced crushed stone cushion with backfilling local soil. To achieve the normal $(\mathrm{Kf}=0.85)$ or increased $(\mathrm{Kf}=0.95)$ degree of compaction it was necessary to provide a layer-by-layer compaction of the soil. As an alternative, the authors proposed a method of soil hardening with the help of strengthening compositions from mineral raw materials. The adjustment of design solutions consisted in the choice of the formula composition of strengthening components and the sequence of their application. It allowed to save material and technical resources (concrete, metal, crushed stone).

There were prepared 3 options to strengthen the soil. In option 1 SC make up to 5\%, in option 2 - up to $10 \%$ and in option 3 - up to $15 \%$ of the volume of soil to be strengthened. The use of each of the options was determined by the condition of the strengthened soil. The creation of optimal humidity of the strengthening composition and maximum density were provided by the introduction of corrective additives in the form of crushed granodiorite and its screening, as well as changes in the percentage of components from mineral raw materials.

There was developed the following technological sequence:

1. Preparation of construction site:

- development of a trench 1.2-1.5 m wide;

- layout of the trench bottom;

- marking the strengthened areas in the trench below the project level;

- selection of soil for laboratory analyses;

- determination of soil moisture and density;

- selection of the strengthening composition for the given soil.

2. Main work:

- loosening the layer of $0.2 \mathrm{~m}$ in depth of the strengthened areas with the ripper (cutter, mini-plow) on the entire width of the trench with the grinding of lumps;

- preparation of the mixture depending on the physical parameters of the soil: humidity and density;

- correction of humidity of the strengthened layer of soil by filling of crushed stone and stone screenings;

- laying of the SC with a layer of 0.005-0.015 m (depending on the content of clay particles in the strengthened layer) on the loosened soil with an excavator and shovels;

- mixing of soil with the SC at a double pass of the ripper;

- irrigation of the packed mixture with watering machines, bringing it to an optimum moisture;

- compaction of the mixture with a small self-propelled vibration roller or a vibration platform with several passes (at least 5);

3. Final work:

- control of the safety of the object during the setting of strength (at least 36 hours);

- monitoring the setting of strength of the soil and below the strengthened layer in the field and laboratory conditions;

- backfilling the trench with an excavator in 36-48 hours.

This option was adopted for execution and showed a positive economic effect.

Reference checking of gaining the strength of soils under the sewer through penetration showed that a soil monolith under the pipes is quickly gaining strength. Within 2 months the deformation module has reached a value of more than $80 \mathrm{MPa}$.

Thus, the results of laboratory and implementation work show that strengthening compositions match harmoniously with the soil. SC not only regulate moisture, but also simultaneously equalize the temperature regime of the strengthened soils. SC absorb moisture and dusty structures, normalizing the moisture content in the soil and eliminating soil heaving. 
The durability and reliability of structures using the compositions made from mineral soil proved a long period of testing. Currently, the above mentioned objects have been operated from 7 to 15 years and they are all in stable condition.

\section{Conclusion}

The introduction of the developed strengthening compositions in the wet soil provide over time the soil monolith homogeneous in strength and structure due to the "crosslinking" of all of its mineral components. Experimental studies and the results of the introduction of the SC on real sites showed that the soil monolith increases, "grows" in depth over time, normalizing the temperature and humidity in depth. Constant heat and humidity conditions without extremes provide stabilization of the soil structure and its foundation. SC drain and strengthen the soil by means of selected components during the entire period of operation of the facility. Depending on the tasks you can pick up soil strengthening compositions and the percentage of different component content: the binder - lime, dolomite and zeolite, enzyme-seal made from proteins and sugars. In addition, there can be introduced the fillers of: fine fraction limestone and brucite screenings, larger fraction - crushed stone and screenings of strong rocks. Extensive experience of the implementation of the SC in the practice of strengthening and stabilization of soil structures showed that the achieved technical result is the prevention of deformation of wet soil by continuous drainage while increasing the strength and water resistance. Strengthening compositions work harmoniously with soils and in combination with other materials, including: geo-synthetic ones, concrete, etc. The use of strengthening compositions can significantly reduce the complexity, the cost of operation of machines and mechanisms and obtain significant savings in material resources.

\section{References}

1. S.M. Zhdanova, Evaluation of the effectiveness of resource-saving methods of stabilizing the subgrade at the Urgal and Emercency track of Far-Eastern Railroad: report on research work (FESTU, Khabarovsk, 2001)

2. S.M. Zhdanova, Study of the thermal-moisture regime of sedimentary embankment bases in the annual cycle. Index of deposited manuscripts. Report on research (final) (FESTU, Khabarovsk, 2002)

3. K. Terzaghi, Theoretical Soil Mechanics (John Wiley and Sons, New York, 1943)

4. S.M. Zhdanova, Calculation-theoretical justification of the bearing capacity of structural elements of the earthen roadbed with improved soils based on mineral compositions properties. Report on research (final) (FESTU, Khabarovsk, 2004)

5. S.M. Zhdanova, Research and development of Resource-saving Technologies in Railway transport of the Far-Eastern region, Inter-university collection of scientific works with international participation (SAMIIT, Samara, 2001)

6. Soil-cement roads: construction handbook: Portland Cement Association (The Association, Chicago, 1949)

7. E. Gregory Halsted, S. Wayne Adaska, T. William McConnell, Guide to CementModified Soil (CMS) (Portland Cement Association, 2008)

8. S.M. Zhdanova, Strengthening the Subgrade on Thawing Permafrost, Monograph (FESTU, Khabarovsk, 2005) 